\title{
UK Housing Stock Models Using SAP: The Case for Heating Regime Change
}

\author{
Martin Hughes ${ }^{1}$, Peter Pope ${ }^{1}$, Jason Palmer ${ }^{2, ~}{ }^{*}$ Peter Armitage $^{3}$ \\ ${ }^{1}$ Cambridge Architectural Research, Cambridge, UK \\ ${ }^{2}$ Cambridge Architectural Research \& Cambridge Energy, Cambridge, UK \\ ${ }^{3}$ SBP Ltd, London, UK
}

\section{Email address:}

martin.hughes@carltd.com (M. Hughes),peter.pope@carltd.com (P. Pope), jason.palmer@carltd.com (J. Palmer), peter.armitage@sbpltd.uk.com (P. Armitage)

${ }^{*}$ Corresponding author

\section{To cite this article:}

Martin Hughes, Peter Pope, Jason Palmer, Peter Armitage. UK Housing Stock Models Using SAP: The Case for Heating Regime Change. Science Journal of Energy Engineering. Vol. 4, No. 2, 2016, pp. 12-22. doi: 10.11648/j.sjee.20160402.11

Received: August 15, 2016; Accepted: August 27, 2016; Published: September 13, 2016

\begin{abstract}
Cutting energy use in housing will play a key role in the UK's efforts to reduce climate change emissions in line with international commitments. Much UK Government policy is based on modelling present and future emissions using assumptions from SAP, the Standard Assessment Procedure. This paper compares SAP-based modelling against measured gas consumption in 405 dwellings that were monitored in the Energy Follow-Up Survey, an extension of the English Housing Survey. The combined EFUS/EHS provides comprehensive information about space heating energy use for a sample of dwellings: detailed physical data, user behaviour, and measured energy use. Very poor model versus measurement agreement is observed at the individual dwelling level - the average difference is $45 \%$. Much better agreement is observed when applying typical EFUS regimes of $20^{\circ} \mathrm{C}$ mean demand temperature, 10 hours of heating a day for weekdays and weekends, and a heating season of six months, and comparing average results. Comparisons for the 405 dwellings and an EFUS subset of 1,191 dwellings are both in agreement to within $2 \%$, whilst average 2010 and 2011 sub-national estimates are in agreement to $3 \%$ of DUKES figures. The authors recommend changing SAP heating regimes to a mean demand temperature of $20^{\circ} \mathrm{C}, 10$ hours of heating a day for weekdays and weekends, and a heating season of six months.
\end{abstract}

Keywords: Household Energy, Energy Model, Cambridge Housing Model, SAP, Green Deal, Energy Follow-up Survey

\section{Introduction}

The UK Climate Change Act requires the UK to reduce greenhouse gas emissions by at least $80 \%$ by 2050 , against base year 1990 values [1]. In 2012 household energy accounted for $29 \%$ of total UK energy consumption [2] so reductions in domestic energy use will play a major role in meeting targets. Housing energy models support the development of policies and initiatives aimed at reducing energy use in homes.

The Cambridge Housing Model (CHM) is a household energy model for England, Great Britain and the UK, and underpins DECC's Housing Energy Fact File (HEFF) [3] and the Energy Consumption in the UK (ECUK) data tables [4]. The CHM is based on the Standard Assessment Procedure
(SAP) and Reduced data SAP (RdSAP) [5]. SAP is a simplified version of BREDEM the BRE Domestic Energy Model [6] and has been regularly used for modelling household energy consumption $[7,8,9,10]$. SAP and RdSAP are also used to estimate savings from energy efficiency improvements made under the Green Deal [11]. In the CHM, SAP calculations have been adapted for use as a national stock model.

The main source of CHM input data is the English Housing Survey (EHS), England's most detailed survey of dwellings [12]. In 2010 the EHS included physical and demographic data on 16,670 properties, representing 22.4 million dwellings in England. The CHM reads in housing data for each representative dwelling, performs building physics calculations, and outputs dwelling-level annual 
energy use and $\mathrm{CO}_{2}$ emissions. The results are scaled to an annual total for England by applying EHS weightings to each of the individual dwelling estimates.

In 2010, space heating accounted for $69 \%$ of total household energy use [2], and is therefore of particular significance. Although the EHS includes hundreds of pieces of data on each dwelling it does not contain information on user heating behaviours. Instead the CHM uses assumed average behaviour for all dwellings:

- The SAP hours of heating of 9 hours a day on weekdays and 16 hours a day at weekends.

- The SAP heating season of 8 months a year.

- An empirically-based demand temperature of $19^{\circ} \mathrm{C}[13$, $14]$ for the living area, rather than the SAP default of $21^{\circ} \mathrm{C}$

The CHM has been subject to vigorous testing, however like all models it uses approximations and assumptions, and is subject to uncertainty $[9,10,14,15,16,30,31]$. Comparison of model outputs against total English household energy use in 2010 based on DUKES figures (Digest of UK Energy Statistics [17]) shows model versus measured electricity use in agreement to within $1 \%$, but the model overestimates gas use by $13 \%$. DUKES data cannot be disaggregated into different uses like water heating, cooking and space heating, but gas consumption is a reasonable proxy for heating use.

There are likely to be a number of reasons for this 'modelling gap'. The SAP method is a standard approach for calculating the energy performance of individual dwellings [18] and is not intended for assessing national household energy use; the SAP algorithms are a substantial simplification of the actual building physics; the model uses the 16,670 dwellings from the English Housing Survey [19] to represent the housing stock; average monthly, regional climate data is used. However, the lack of behavioural data may be a key factor.

Until recently it has been very difficult to validate the model against anything other than the national household energy statistics in DUKES. However in 2010-11 an Energy Follow Up Survey (EFUS) linked to the English Housing Survey was carried out to collect new data about household energy use [20, 21, 22]. Unlike earlier work, gas and electricity use were monitored and user heating behaviours were surveyed or monitored. This provided a much richer seam of data, with comprehensive information about space heating energy use for a sample of dwellings: detailed physical data, user behaviour, and measured energy use. By modifying the $\mathrm{CHM}$ to include heating regimes for individual dwellings, and considering only dwellings with full heating data, a more complete model versus measurement comparison was feasible. This enabled a fuller investigation of the performance of the CHM and SAP in predicting energy use for heating, and a calibration of the default model heating behaviour assumptions. This comparison and calibration are outlined here.

The present study builds on earlier research using housing energy models to examine the potential for energy and $\mathrm{CO}_{2}$ savings [23, 24]. It also builds on comparisons of actual against modelled energy use carried out in the 1990s, which ultimately led to revisions to the household energy models of the period [25]. More recent inter-model comparisons such as [26] do not consider actual, monitored energy data. There have been follow-up surveys to past iterations of the English housing survey in 1996 and 2001, focusing on energy use, however data that would support model versus measurement comparison were never published. More recent data from the National Energy Efficiency Data-Framework (NEED) (e.g. [24]) could theoretically be matched against households participating in the English Housing Survey to carry out modelling for the purposes of comparison against measured NEED data, but this matching is very difficult, and privacy/confidentiality issues raised in the matching process would be extremely difficult to overcome.

The paper begins with a description of the model and of the EFUS. The monitored data for heating regimes and the measurement of actual energy use are reported, along with the interpretation of this information. This is followed by a description of some modifications to the CHM hours of heating calculations. The paper concludes with a comparison of the modelled and measured values for space heating energy use, at both individual dwelling and aggregate levels.

\section{The Model}

The Cambridge Housing Model is a bottom-up building physics, national-level stock model based on the SAP 2009 methodology for calculating the energy performance of individual dwellings [5]. SAP is intended primarily for checking compliance with Part L of the Building Regulations [18], and focuses on regulated energy use which comprises mainly space and water heating, fixed lighting, ventilation and pumps. SAP ratings do not include energy use associated with electrical appliances or cooking, however the CHM needs to include this: appliances energy use is calculated based on SAP Appendix L, and cooking energy use is based on BREDEM-8 [6] with adjustments relating to cooking heat gain.

The SAP heating calculation is based on an energy balance, taking account of fabric heat loss, solar gains, ventilation characteristics, the efficiency of heating systems, and fuel sources. In the original CHM the only heating calculation changes made to the SAP formulation are the use of regional, year-specific climate data and the use of a $19^{\circ} \mathrm{C}$ demand temperature for the living area. The CHM is openly available for peer review ${ }^{1}$ and is described in detail in [28]. SAP- RdSAP (Reduced Data SAP) is described in [5].

Some 120 pieces of data from the EHS are used as inputs to the model, describing each dwelling. The EHS data includes dimensional and geometric data, details on the building fabric, information on heating and hot water

1 The Cambridge Housing Model can be downloaded from the UK Government website: https://www.gov.uk/government/organisations/department-of-energyclimate-change/series/domestic-energy-fact-file-and-housing-surveys 
systems, the dwelling age and type, the number of occupants and the location. For physical input data which are not directly available from the EHS, values are derived from relevant EHS parameters in conjunction with standard tables from RdSAP [5]. For example, wall U-values are not collected but derived based on wall type and building age. The 405 EFUS dwellings analysed here are a subset of the dwellings in the 2010-11 EHS.

In the absence of dwelling-by-dwelling heating demand temperature, hours of heating and heating season data, the original model adopts figures for typical (average) heating regimes across the UK and applies them to all dwellings see Tables 1 and 2. For the analysis of the 405 EFUS dwellings, the default heating behaviours are replaced with the new EFUS dwelling-by-dwelling data as described in the next sections; the original CHM has been adapted to accept behavioural inputs at the individual dwelling level.

Table 1. Average hours of heating calculated from the 405 gas-heated EFUS dwellings, compared to the SAP and original CHM default. The CHM assumes two periods of heating per day, separately for weekdays and weekends.

\begin{tabular}{lll}
\hline & Standard SAP: hours of heating on (hours) & Mean EFUS values: hours of heating on (hours) \\
\hline Week day time period 1 & 5.0 & 7.80 \\
Week day time period 2 & 4.0 & 1.99 \\
Weekend day time period 1 & 12.0 & 8.72 \\
Weekend day time period 2 & 4.0 & 1.68 \\
\hline
\end{tabular}

Table 2. Average heating season calculated from the 405 gas-heated EFUS dwellings, compared to the original CHM-SAP default (1=on, 0=off). Values indicate the monthly proportion of time that heating is assumed to be turned on.

\begin{tabular}{lll}
\hline Monthly fraction heating on & Standard SAP: proportion of month (\% month) & Mean EFUS values: proportion of month (\% month) \\
\hline Jan & 1 & 1.00 \\
Feb & 1 & 0.92 \\
Mar & 1 & 0.44 \\
Apr & 1 & 0.20 \\
May & 1 & 0.08 \\
Jun & 0 & 0.06 \\
Jul & 0 & 0.06 \\
Aug & 0 & 0.07 \\
Sep & 0 & 0.19 \\
Oct & 1 & 0.69 \\
Nov & 1 & 0.98 \\
Dec & 1 & 1.00 \\
\hline
\end{tabular}

In the CHM gas use may comprise main heating, secondary heating, water heating and cooking use; it is assumed that this is also the case for the actual consumption. The CHM (and SAP) assumes secondary heating use based on the same regime as the main heating use, and estimates water heating and cooking energy use based on the number of occupants. On average, water heating accounts for around $15 \%$ of domestic energy use, and cooking for around $2 \%$ (Palmer and Cooper, 2014). When considering model versus measurement comparisons it should be recognised that only behavioural data on space heating is available here.

\section{The Energy Follow up Survey}

The Energy Follow Up Survey carried out surveys and monitoring of 2,616 English homes in 2010 and 2011, with the intention of informing government policy on energy efficiency. Data from the survey was made available to the research community in early 2014 . Energy consumption data consists of meter readings taken on 1,345 homes. The length of heating season data comes from interviews on 2,464 homes, with interviewees asked to report the typical months of the year when they turn their heating on and off. The internal demand temperature and hours of heating data is based on information collected by internal temperature loggers. These loggers were located by the surveyors in the living room, hallway and main bedroom of each dwelling, at eye level, away from heating sources, and out of direct sunlight. The CHM (and SAP and BREDEM) assume there are two heating areas: the living area and the rest of dwelling. Given a figure for the living area demand temperature, the default CHM-SAP-BREDEM assumption bases the rest of dwelling temperature on the calculated heat loss and the type of heating control, where 'rest of dwelling' refers to all heated areas apart from the living room - bedrooms, hallway, kitchen, etc $[5,6]$. Retaining this model simplification here, only the EFUS living room logger data is used. The loggers record the average internal temperature at 20-minute intervals, with measurements taken over the course of three complete months from the start of November 2010 to the end of January 2011.

The survey methods were described in detail by the Building Research Establishment [20, 22], and the overall findings are summarised in [21]. The living room logger recorded the temperature reached just before the heating turns off. Here it is assumed that this equates to the living area demand temperature. The times at which the heating was turned on and turned off were estimated from logged temperature gradients, to give heating durations.

Two approaches were assessed: automated analysis of daily profiles and a visual inspection of monthly averages [22]. Initial trials established that that the automated 
approach could produce misleading results when dealing with small temperature variations. Furthermore the approach, which needed to anticipate the shape and range of heating curves, was unable to effectively handle data with only weak or inconclusive patterns. For these reasons the more subjective, analyst-based approach was used. Analysts identified the on and off times for up to three periods per day, separately for each of the three monitored months, and separately for weekdays and for weekend days, for each dwelling. Once again separating weekdays and weekends, a daily average profile was computed from all the readings in each month [22]. On this basis, three average monthly final temperatures and heating durations were determined, separately for weekdays and weekends, and for each of the three monitored months, for each dwelling. Demand temperatures were monitored for 823 homes and hours of heating monitored for 760 homes.

The averaging and inspection of data for trends in heating pattern required somewhat subjective judgement by the analyst, and is not as repeatable as an algorithmic approach, but it was deemed more accurate/effective here in determining typical monthly use patterns (BRE, 2013c). Undoubtedly this approach introduces a degree of error into the process, as is the case with any such interpretation of data. In the analysis presented here, no attempt was made to quantify or account for the uncertainty introduced as a result of this approach. The EFUS data was further interpreted for use in the CHM as described in the following sections.

Dwelling level gas and electricity meter readings cannot be disaggregated into different forms of energy use. This is a particular problem for electricity as even in electrically heated dwellings for which there is heating behaviour data, a large portion of electricity use is not for space heating (around $10 \%$ of UK dwellings have electric heating [3]). There is no EFUS data on user behaviour relating to electric appliances or lighting. For these reasons model versus measurement electricity use comparisons have not been addressed here. Instead the focus is on gas use, with an emphasis on space heating.

In the EFUS there is a full set of gas meter readings, demand temperatures, hours of heating and heating seasons for 405 dwellings that use gas as the main heating fuel. The analysis presented here is based around these 405 dwellings.

\subsection{Demand Temperature}

The CHM uses a single internal demand temperature for the living area, for the entire heating season. A comparison value is generated from the monitoring data by calculating a single weighted average daily value from the average weekday/weekend EFUS monthly living room figures, for each of the 405 dwellings. This was used in the 405 dwelling $\mathrm{CHM}$ as the input demand temperatures for the whole heating season.

The distribution of the average demand temperatures across the 405 dwellings is shown in Figure 1. The mean is $19.8^{\circ} \mathrm{C}$, compared to the default $\mathrm{CHM}$ value of $19^{\circ} \mathrm{C}$ and the SAP value of $21^{\circ} \mathrm{C}$. The standard deviation is $2.14^{\circ} \mathrm{C}$ and the median is $20.02^{\circ} \mathrm{C}$

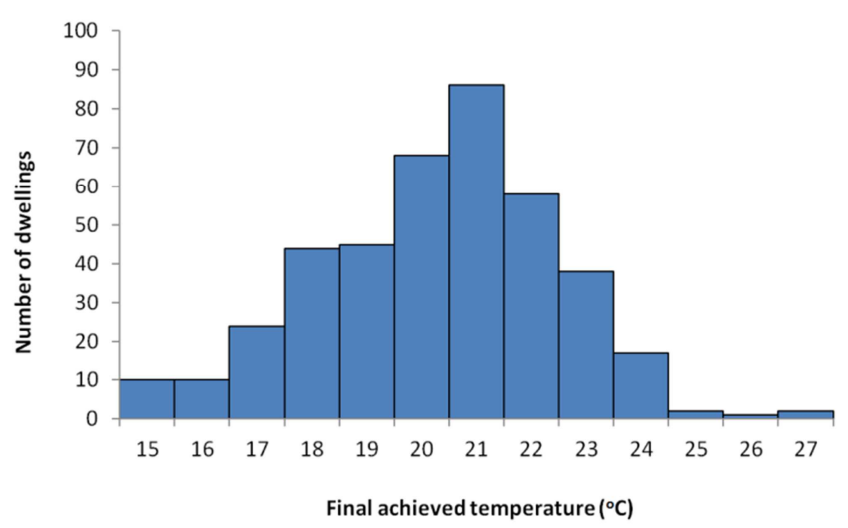

Figure 1. Distribution of final achieved internal temperatures across the 405 EFUS dwellings; this data is used for internal demand temperatures in the 405 dwelling CHM considered here.

\subsection{Hours of Heating}

The CHM assumes two periods of heating per day, separately for weekdays and weekends - see Table 1, whilst the EFUS data comprises average durations for up to three periods in a day separately for weekdays and weekends for each of the 405 dwellings. For dwellings where the survey recorded only a single heating period, it is assumed that the second CHM period has zero hours on; for dwellings where the survey recorded three heating periods the second and third periods' data are combined. These figures are used in the CHM as the input hours of heating for the whole heating season.

Table 1 shows the average hours across the 405 dwellings, for each of the two time periods for weekdays and weekends; the original CHM- SAP defaults are included for comparison. The distributions for the average total hours of heating on for weekdays and weekend days across the 405 dwellings are shown in Figure 2. The mean weekday figure is 9.8 hours on and the mean weekend day figure is 10.4 hours on. Whilst the weekday figure is quite similar to the CHM-SAP default of 9 hours, the weekend figure is significantly different to the CHM-SAP default of 16 hours on. For weekdays the standard deviation is 4.3 hours and the median is 8.8 hours, whereas for weekends it is 4.3 hours and 9.7 hours respectively.

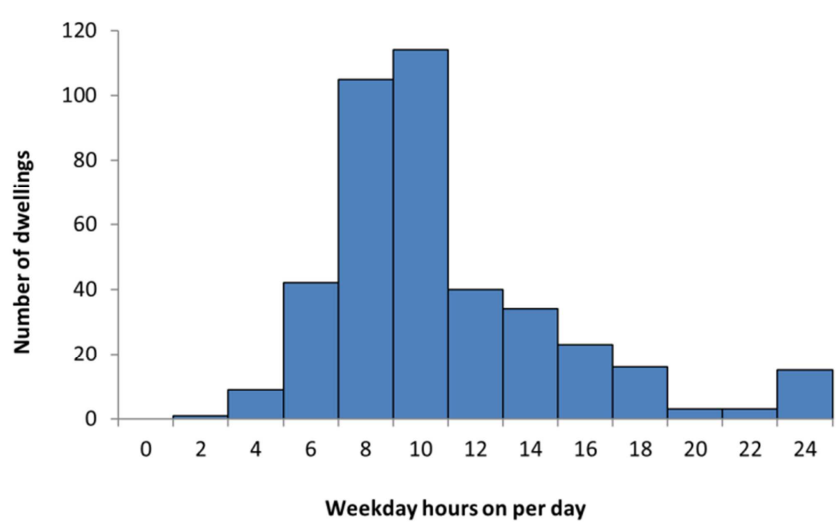




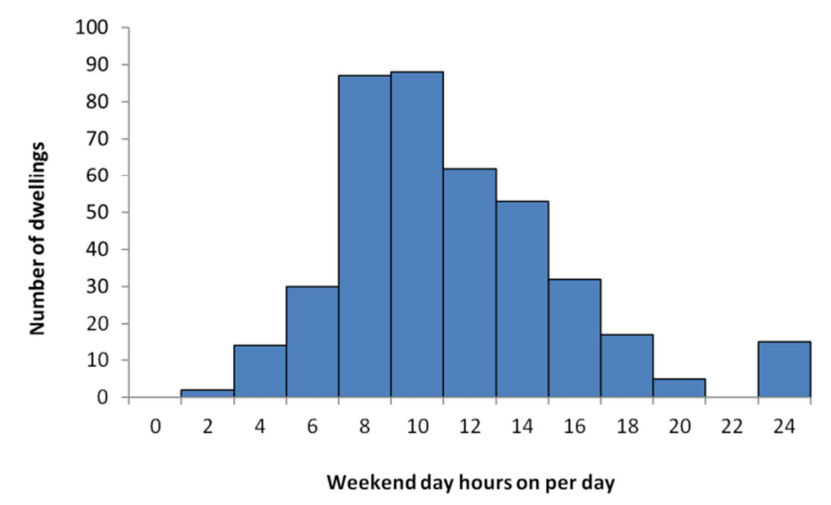

Figure 2. Distribution of weekday and weekend day heating hours on, across the 405 EFUS dwellings.

\subsection{Heating Season}

Homeowners were asked to report the typical months of the year when they turn their heating on and off $[20,22]$. Here this has been interpreted as a heating season running from the start of the month 'on' to the start of the month 'off', for each of the 405 dwellings. In the CHM-SAP the heating season is expressed in terms of a binary array of $1 \mathrm{~s}$ and 0 s representing heating on and heating off for each of the twelve months. The original default is the same heating season for all dwellings, spanning 8 months from October to May inclusive; see Table 2. For the 405-dwelling analysis this default data is replaced with the EFUS figures for each dwelling.

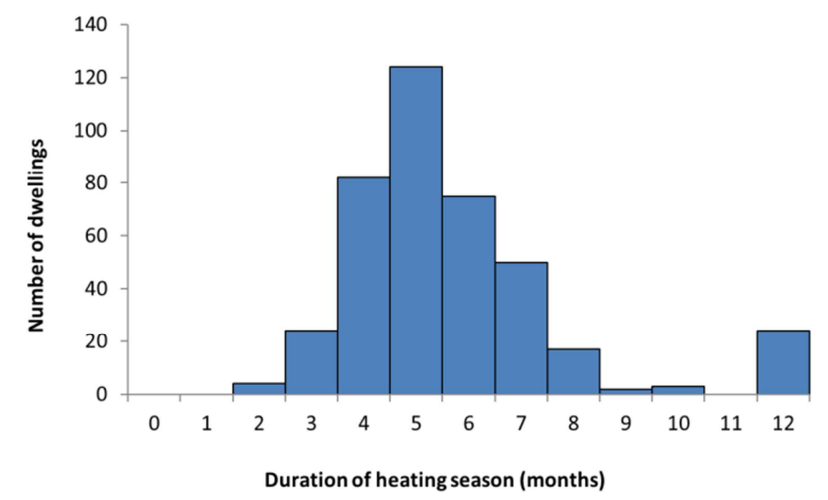

Figure 3. Distribution of heating season duration across the 405 EFUS dwellings.

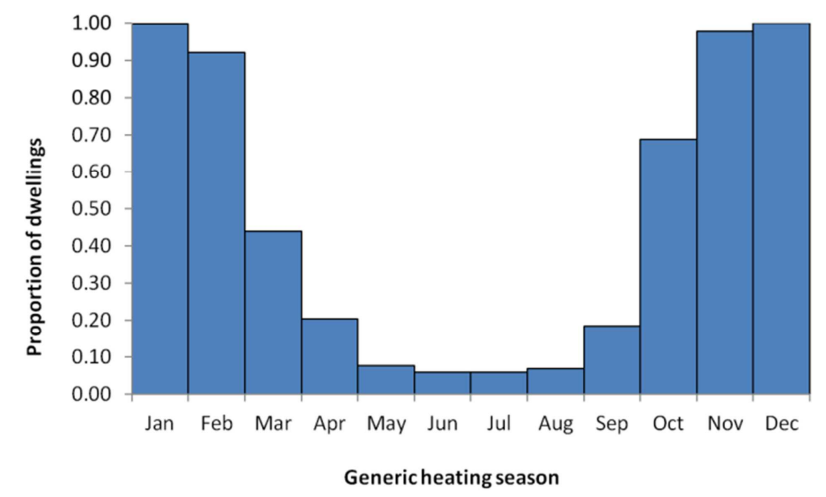

Figure 4. Generic heating season: average proportion of each month that heating is turned on, based on 405 EFUS dwellings.
The distribution of heating season durations for the 405 dwellings is shown in Figure 3. Figure 4 and Table 2 further show the generic heating season - that is the average proportion of each month that heating is turned on, across the 405 dwellings. The mean heating season duration is 5.7 months with a standard deviation of 2.07 months, and median of 5.0 months.

\subsection{Measured Gas Consumption}

Initial meter readings were taken by surveyors at some point between April and September 2010. A follow-up reading was then taken by one of a number of routes depending on access: official meter readers, the householder, direct from the energy supplier, or by specialist personnel [20]. The resulting range of consumption periods spanned between 15 and 30 months, across the 405 dwellings. All of the meter readings covered the single 12-month period spanning mid-November 2010 to mid-November 2011. The figures were therefore adjusted to approximate a single value (per dwelling) for this period; the figures were scaled to span a single year and weather adjusted to align to November 2010 to November 2011 [20]. The result is a single annual gas consumption figure per dwelling, which can be compared against the corresponding model estimate.

The distribution of annual gas consumption for the 405 dwellings is shown in Figure 5. The mean value is $16,926 \mathrm{kWh}$, the standard deviation is $10,754 \mathrm{kWh}$ and the median is $14,110 \mathrm{kWh}$. The distribution is clearly skewed by a small number of users consuming large amounts of energy. This leads to the large standard deviation and the large difference between mean and median values.

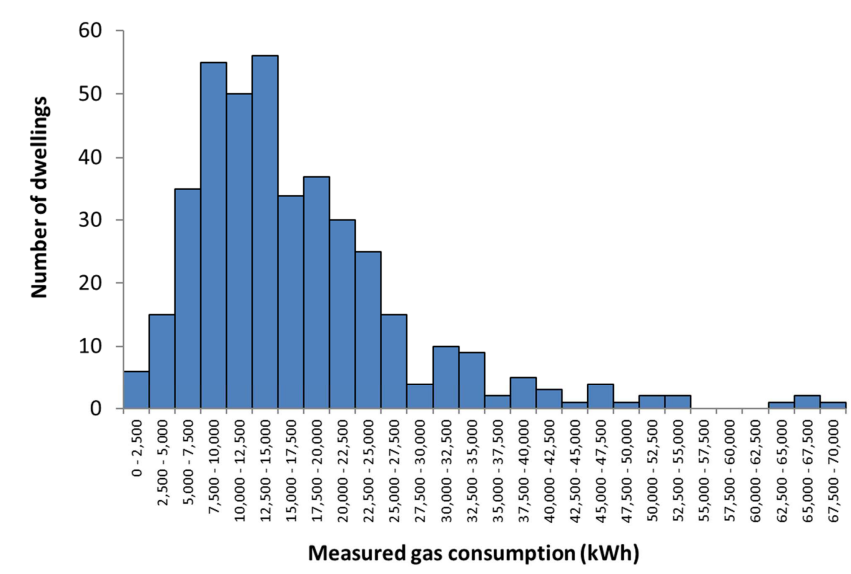

Figure 5. Distribution of measured gas consumption across the 405 EFUS dwellings, covering the single year from mid November 2010 to mid November 2011.

\section{Modifications to the Hours of Heating Calculation}

Previous sensitivity analysis of the CHM [28, 16] revealed that when the hours of heating are significantly varied from the default SAP values the model does not respond realistically: when the hours of heating are substantially 
reduced the model still estimates high space heating energy use - see the Original CHM curve in Figure 6. This is not a fault with the SAP calculations [5], which were designed to be effective at the default behavioural values, but is a consequence of using those calculations outside of their intended purpose. Because the hours of heating data varies considerably across the 405 EFUS dwellings (see Figure 2) a modification to the hours of heating calculation has been considered here to ensure that the model response is appropriate when using individual dwellings' behaviours.

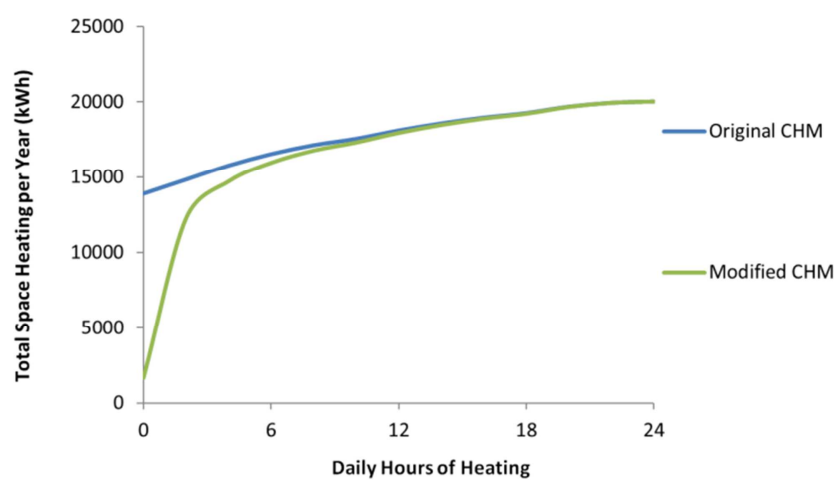

Figure 6. Example of the effect of modifying the hours of heating CHM-SAP calculation to more realistically estimate consumption for low hours of heating; the modified calculation is used for all model results presented here.

The total heating requirement in the CHM-SAP is based on the concept of monthly Mean Internal Temperature (MIT) [5, 6]. The MIT is used to calculate the average monthly heat transfer between the dwelling interior and the external environment. The MIT is calculated by considering the change in internal temperature over the course of a typical day. This calculation assumes that during heated periods the dwelling starts at the set point temperature, effectively heating up instantly, and in unheated periods the internal temperature slowly falls from the set point toward the background temperature. In SAP, the time taken for the temperature to fall is given by the time constant $t_{c}$, based on the Thermal Mass Parameter and the Heat Loss Parameter [5, $6]$. The time that the heating is off then determines whether the dwelling has enough time to cool to the background temperature, see Figure 7.

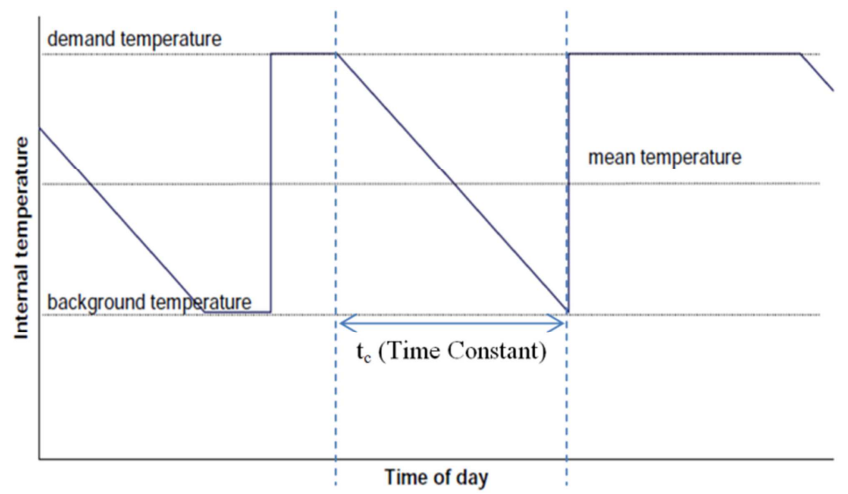

Figure 7. Daily variation of temperature assumed in SAP, based on BREDEM 8 [6].

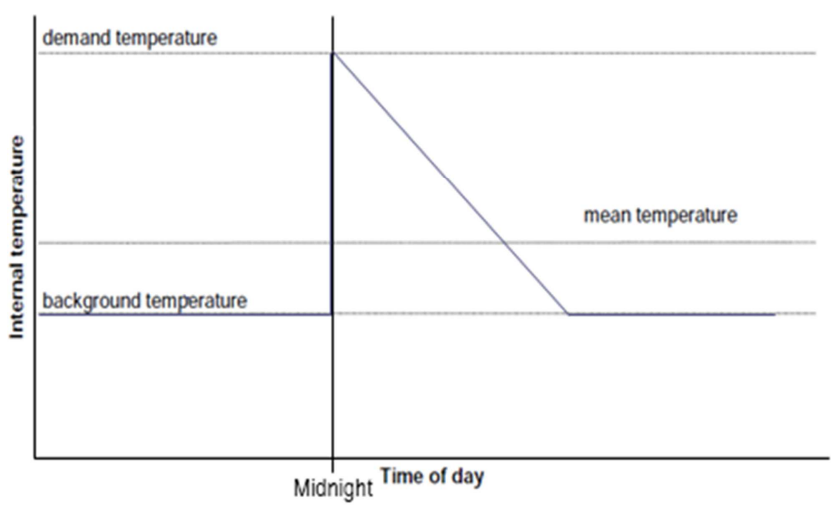

Figure 8. Effective internal temperature profile with zero hours of heating, taken from BREDEM [6].

The issue with this method is that for very short or zero hours of heating it is still assumed that the dwelling starts at the set point, with the temperature falling immediately. Therefore until a time $t_{c}$ has passed, the internal temperature is above the background temperature, so the MIT is also above the background temperature. This leads to a non-zero estimate of heating consumption even for zero hours of heating, see Figure 8.

Ideally the model would account for the time taken to heat the dwelling to the demand temperature, as is the case in reality. Alternative modelling approaches are available, for example dynamic simulation models which do take account of the time taken to heat the dwelling. However, such models also require more extensive data and much greater computational effort, and are not a viable alternative to the SAP-based model here. Instead a compromise approach has been sought here, with the SAP heating requirement algorithm being modified to give response behaviour similar to a dynamic model. This was achieved by modelling a range of dwellings from the EHS in IES Virtual Environment (IES VE), a dynamic modelling software tool ${ }^{2}$. Each model was tested using eight different sets of heating hours ranging from zero to 24 hours of heating per day, during the heating season. The dynamic simulation models consistently gave a logarithmic response to the number of hours of heating, in contrast to the almost linear response from the CHM. Therefore, to modify the $\mathrm{CHM}$ a factor was applied to $t_{c}$ that depends on the number of hours of heating, $H$ :

$$
\text { Zero Hour Adjustment=1- }\left(25-\mathrm{H}^{-1}\right)
$$

This effectively reduces the time taken for a modelled dwelling to return to the background temperature after heating starts, for short heating periods. This produces a more logarithmic response, but also achieves approximately the same response as the original algorithm when the default SAP hours of heating are applied, as shown in Figure 6. This formulation (1) is used in the version of the model used here, and is available for other researchers as a switch in the current version of the CHM.

\footnotetext{
2 Integrated Environmental Solutions: http://www.iesve.com/
} 


\section{Results: Model Versus Measured Comparison}

\subsection{Comparisons at the Dwelling Level}

A version of the CHM was generated with data on the 405 EFUS dwellings, including individual dwelling heating behaviours and employing the hours of heating adjustment, for direct comparison against the EFUS gas meter data. The EFUS measurements relate to the period from November 2010 to November 2011. To make a direct comparison monthly climate data was generated covering this period, based on the original CHM 2010 and 2011 monthly regional climate data.

The resulting model versus measurement comparison at the individual dwelling level is shown in Figure 9. The $y=x$ parity line is also shown. If the model with heating regimes accurately predicted actual gas use, all points would lie on this line.

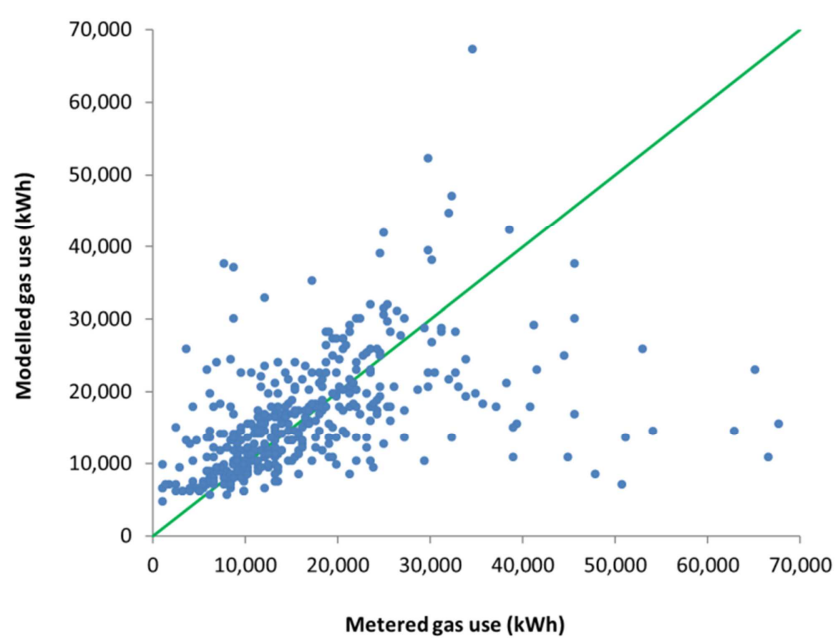

Figure 9. Measured versus modelled annual gas use for 405 EFUS $d$ wellings over the year mid November 2010 to mid November 2011. The $y=x$ parity line is shown.

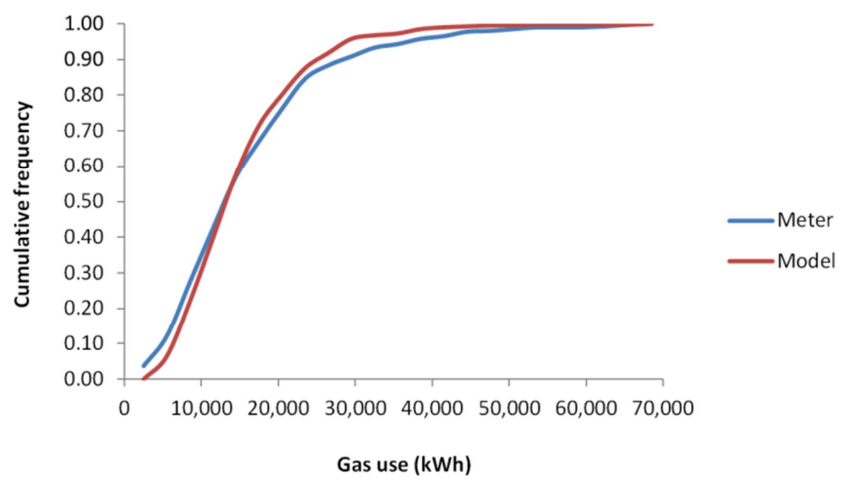

Figure 10. Cumulative frequency distribution of the measured and modelled gas use across the 405 dwellings over the year mid November 2010 to mid November 2011.

Across the 405 dwellings the average model estimate is $16,149 \mathrm{kWh}$, compared to an average measurement of $16,926 \mathrm{kWh}$. That is a model underestimate of $4.6 \%$. Figure
10 shows the cumulative frequency distribution of the measured and modelled gas use across the 405 dwellings, while Figures 11 to 15 show comparisons of the average model versus measurement values at several categorical levels: by house type, age, tenure, floor area and SAP rating. The number of dwellings in each category is shown in brackets below the category name, and 90\% confidence intervals indicate the range of values across the dwellings within each category.

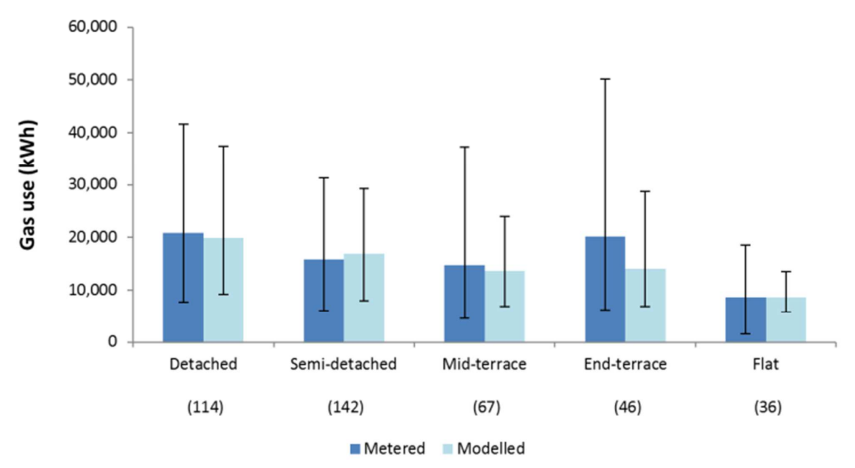

Figure 11. Comparison of average measured and modelled gas use across the 405 dwellings, by house type. Figures in brackets state the number of $d$ wellings in each category, and $90 \%$ confidence intervals indicate the range of values across the dwellings in each category.

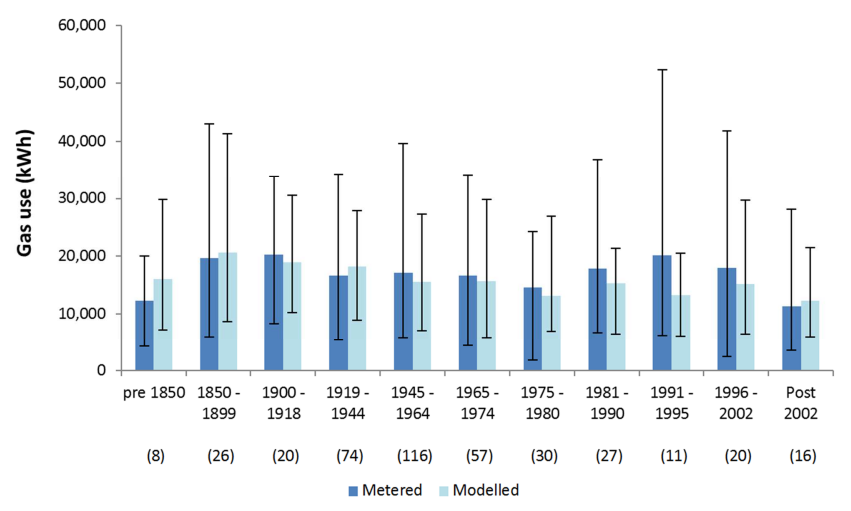

Figure 12. Comparison of average measured and modelled gas use across the 405 dwellings, by house age band. Figures in brackets state the number of dwellings in each category, and $90 \%$ confidence intervals indicate the range of values across the dwellings in each category.

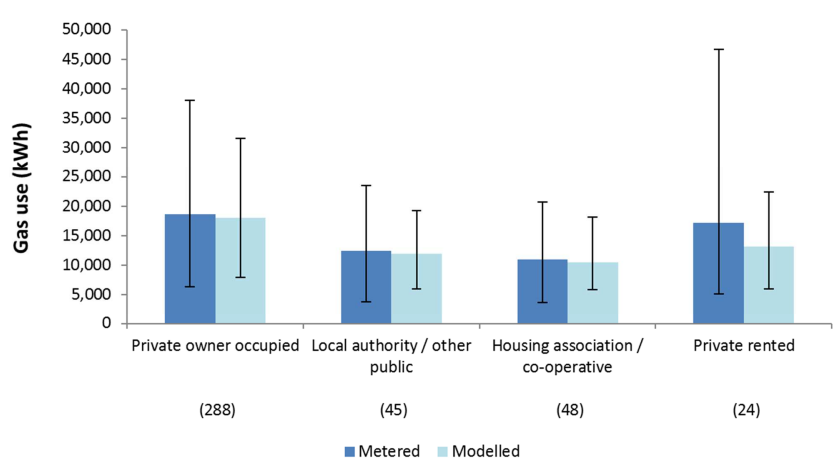

Figure 13. Comparison of average measured and modelled gas use across the 405 dwellings, by tenure. Figures in brackets state the number of dwellings in each category, and 90\% confidence intervals indicate the range of values across the dwellings in each category. 


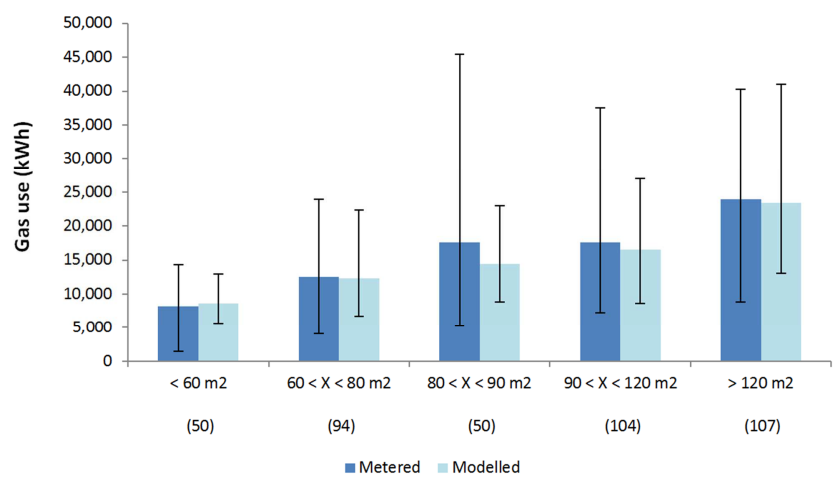

Figure 14. Comparison of average measured and modelled gas use across the 405 dwellings, by floor area. Figures in brackets state the number of dwellings in each category, and $90 \%$ confidence intervals indicate the range of values across the dwellings in each category.

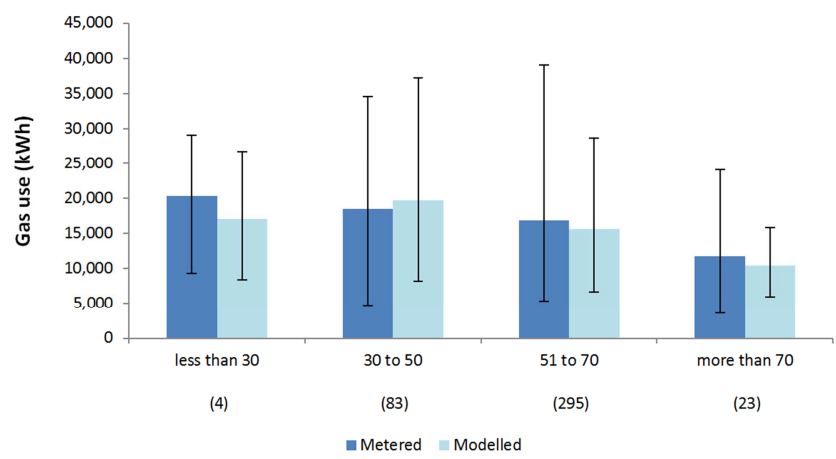

Figure 15. Comparison of average measured and modelled gas use across the 405 dwellings, by SAP rating. Figures in brackets state the number of dwellings in each category, and $90 \%$ confidence intervals indicate the range of values across the dwellings in each category.

The cumulative distribution comparison in Figure 10 shows apparently good agreement, both in terms of the range of results and the density of the results. The categorical plots also generally show reasonable agreement, with some exceptions: end terraces (46 dwellings), 1991-1995 properties (11 dwellings), private rented ( 24 dwellings), floor areas in the range $80 \mathrm{~m}^{2}$ to $90 \mathrm{~m}^{2}$ (50 dwellings), and SAP scores less than 30 (4 dwellings) - although this final comparison is for a very small sample. Values in brackets indicate the number of the 405 sampled dwellings in each of these categories.

However, the most obvious feature of the results is the high level of scatter shown in Figure 9 - that is the high level of disagreement between the measured energy use and the model estimates at the individual dwelling level. On average the estimates are out by $45 \%$ compared to the meter data: the root mean squared error is $10,060 \mathrm{kWh}$. At the extreme, results are out by a factor of eight, in both directions. Even allowing for outliers, $8 \%$ of the model estimates are at least twice the measured value whilst $6 \%$ are less than half the actual value; $60 \%$ of the model estimates are out by at least $20 \%$. Both the cumulative plot (Figure 10) and the histograms of categorical averages (Figures 11 to 15) actually mask the true extent of the underlying disagreement between the model outputs and the measured energy use.

This level of disagreement is unexpected given the relatively comprehensive model input dataset used: individual dwelling physical data, individual dwelling heating user behaviour, monthly, regional climate data, and individual meter readings. These results suggest that the CHM-SAP space heating algorithms do not give accurate results when applied to the analysis of individual dwellings.

It should be noted that the nature of the results is comparable when using the original SAP hours of heating algorithm; that is the adjustment (1) is not the source of the observed disagreement. On average the estimates based on the original SAP hours of heating algorithm are out by $54 \%$ compared to the meter data, and the root mean squared error is $10,649 \mathrm{kWh}$.

\subsection{Comparisons at the Macro Level}

Nominally, the CHM is used to estimate energy consumption at the sub-national and national levels using typical heating regimes: SAP default assumptions and an assumed $19^{\circ} \mathrm{C}$ average demand temperature based on empirical data [13, 14]. However, the EFUS behavioural data offers alternative typical regime information: the average demand temperature from the 405 dwellings of $19.8^{\circ} \mathrm{C}$, the average hours of heating shown in Table 1, and the average heating season shown in Table 2. Furthermore, the CHM is usually assessed only against DUKES level annual figures, but the EFUS offers additional sources of aggregate figures: a total of 1,191 gas heated dwellings had meter readings taken in the EFUS, only 405 of which also had full heating regime data. Therefore a series of model versus measurement comparisons are made here using the typical EFUS regime data:

- Average gas use across the 405 'core' EFUS dwellings.

- Average gas use across the 1,191 gas heated EFUS dwellings.

- Average gas use across all English dwellings in 2010.

- Average gas use across all English dwellings in 2011.

Here English level comparisons are made against DUKES data [17], scaled to England.

Table 3 shows average measured versus modelled gas use across the 405 EFUS dwellings. Here both the original CHM regimes and the typical EFUS regimes are considered. In addition, the average figure based on the individual level regime data is shown for completeness. The model using the average regime shows the best agreement, with a mean value of $16,614 \mathrm{kWh}$ - an underestimate of $1.9 \%$ compared to the average measurement. The average output from the model using individual regimes underestimates the measured value by $4.6 \%$, whilst the model using the original $\mathrm{CHM}$ regimes overestimates the measured value by $6.4 \%$.

Table 3 also shows average measured versus modelled gas use across the 1,191 gas heated EFUS dwellings. Again results for both the original CHM regimes and the typical EFUS regimes are shown. The model using the average regime has a mean value of $14,153 \mathrm{kWh}$, an underestimate of $1.9 \%$ compared to the average measurement of $14,427 \mathrm{kWh}$. For comparison, the model using the original $\mathrm{CHM}$ regime assumptions overestimates the average meter reading by $6.1 \%$. 
Table 3. Comparison of average measured and modelled gas use across the 405 dwellings and across 1,191 EFUS dwellings. Both sets of model results are shown using the original CHM heating regimes and the new typical regime based on 405 dwellings, and the 405 dwelling comparison also considers model results using regimes for individual dwellings.

\begin{tabular}{lllll}
\hline & 405 dwellings & \% difference & $\mathbf{1 , 1 9 1}$ dwellings & \% difference \\
\hline Original CHM regime & 18,016 & $+6.4 \%$ & 15,306 & $+6.1 \%$ \\
Meter & 16,926 & - & 14,427 & - \\
New typical regime & 16,614 & $-1.9 \%$ & 14,153 & $-1.9 \%$ \\
Individual dwellings regimes & 16,149 & $-4.6 \%$ & - & - \\
\hline
\end{tabular}

Using the 405-dwelling typical regimes, the consistent difference between average model and measured outputs for both the 405 and 1,191 samples is encouraging - both showing a model underestimate of around $2 \%$. However it is worth mentioning the substantial difference in the average meter readings between these two samples, with the 405 dwellings having an average of $16,926 \mathrm{kWh}$ against the 1,191 dwelling average of $14,427 \mathrm{kWh}$. There could be a number of reasons for this, including the possibility that either of the physical datasets are not truly representative of the full stock, and/or that the regimes for the 405 dwellings is not truly representative. This second possibility is countered by the good model versus measurement agreement at the average level. Furthermore, the EFUS actually includes a total of 669 dwellings with full heating regime data, and this sample has an average of $20.0^{\circ} \mathrm{C}$ demand temperature, average of 10.5 hours of heating on weekdays and 11.0 hours on weekend days, and an average heating season of 5.8 months. This is quite consistent with the 405 dwellings regime data. Further work is required to establish the reasons for the observed difference in average measured data.

Table 4 shows average measured versus modelled gas use at the sub-national level of all English dwellings. Again, results for both the original CHM regimes and the typical EFUS regimes are shown. Measurements are based on DUKES UK figures [17] for both 2010 and 2011, adjusted to English-equivalent values by scaling according to the numbers of dwellings at the national and sub-national levels $[2,4]$. The corresponding models use the 2010 and 2011 EHS datasets and monthly climate data for the 2010 and 2011 calendar years.

Table 4. Comparison of average measured and modelled gas use for the 2010 and 2011 consumption in England; measurements are based on DUKES figures [17]. Model results are shown using the original CHM heating regimes and the new typical regime based on 405 dwellings.

\begin{tabular}{|c|c|c|c|c|}
\hline & 2010 & $\%$ difference & 2011 & $\%$ difference \\
\hline Original CHM (England) & 16,537 & $12.7 \%$ & 12,640 & $16.3 \%$ \\
\hline DUKES (England) & 14,670 & - & 10,869 & - \\
\hline New regime CHM (England) & 14,233 & $-3.0 \%$ & 11,208 & $3.1 \%$ \\
\hline
\end{tabular}

For 2010 the model using the average regimes underestimates the average DUKES figure by $3.0 \%$, whilst the model using the original $\mathrm{CHM}$ regime overestimates DUKES by $12.7 \%$. However, for 2011 the model with the average regimes overestimates the average DUKES figure by $3.1 \%$, whereas the model with the original CHM regimes overestimates DUKES by $16.3 \%$. The magnitudes of the average 2010 and 2011 model versus measurement discrepancies are consistent with the 405 and 1,191 dwellings comparison of averages. However the nature of the 2011 results - an overestimate - is inconsistent and requires further analysis. Undoubtedly, however, these results suggest that stock level analysis would be substantially improved by replacing the original CHM typical space heating regime with the average EFUS regime.

\section{Discussion and Conclusions}

A significant decrease in domestic energy use will be necessary if the UK is to meet energy reduction targets. Household energy models such as the Cambridge Housing Model, a SAP-based stock level model, are important tools for developing appropriate initiatives. A comprehensive input dataset has become available for the CHM as a result of the Energy Follow Up Survey to the 2010-11 English Housing
Survey. This marries together detailed physical data, user heating regimes, and measured energy use for a sample of 405 dwellings. As a result, a model versus measurement comparisons of household gas use has been reported here with a focus on space heating use, at the level of individual dwellings and at a number of aggregate levels including the sub-national English level.

Results of the analysis at the level of the 405 dwellings suggest that whist agreement is reasonably good in terms of average use with the model underestimating by $4.6 \%$, at the individual dwelling level results are very poor: on average individual model estimates are out by $45 \%$, with $60 \%$ of dwellings out by at least $20 \%$. Given the comprehensive nature of the input dataset this is a somewhat surprising result and suggests that the CHM-SAP space heating algorithms may not give accurate results for individual dwellings.

There are likely to be a number of potential reasons for the observed high level of disagreement at the individual dwelling level. Some of these stem from simplifications or weaknesses in the model:

- The building physics model is a substantial simplification of reality.

- Calculations are made on a monthly basis, using average annual user behaviours. The small-scale dynamic properties of the system are ignored. 
- The model versus measurement comparison is impacted by the limitations of the water heating and cooking energy use data and algorithms.

- General underlying assumptions in the CHM and SAP may be incorrect and/or gas use may be affected by information not contained in the model. For example, the distribution of gas use in Figure 5 shows a large proportion of very low values even though all dwellings use mains gas as the main heating fuel. This could be due to temporary occupation (with unoccupied winter periods), frugality/fuel poverty (so-called "underheating"), or other factors which are omitted from the analysis.

- The model calculations are subject to possible errors.

- The effects of the micro climate are ignored: actual localised external temperatures and/or wind-speeds are not accounted for in the model.

There are also possible sources of disagreement stemming from the input data used in the comparisons:

- There is considerable averaging of the EFUS behaviours data for all of the 405 dwellings.

- A number of assumptions and simplifications are made around the heating regimes, such as equating the monitored final achieved temperature to the demand temperature.

- The measured EFUS gas meter data has to be adjusted to generate annualised mid November 2010 to mid November 2011 information.

- There is necessarily some simplification of the EHS physical data in order to align with the required model inputs.

- All input data is subject to uncertainty and mismeasurement. This includes the physical EHS data, the monitored/surveyed EFUS behavioural data, the EFUS meter readings, the monthly climate data and the RdSAP default data. The somewhat subjective approach to determining average daily heating patterns, and the associated achieved demand temperatures, has been highlighted as a particular potential source of erroruncertainty.

More research is needed to explore why it is that some dwellings' energy use for space heating is so much higher or lower than CHM/SAP estimates. However, these results raise fundamental and worrying issues for SAP, which is used in the UK Building Regulations to assess the energy performance of new homes, and is the basis for assessing energy savings from the Green Deal - the Government's flagship policy to provide incentives to retrofit existing homes. The accepted wisdom is that although SAP does not accurately predict actual energy use for heating in individual homes, this is because nearly all homes have different heating regimes from the 'standard' assumptions in SAP. By implication, with more accurate information about heating regimes, SAP would give estimates of energy use for heating that are at least close to metered gas use. This work shows that this presumption is unfounded - some homes use many times more energy than the CHM/SAP predicts, while others use only a fraction of the predicted energy use, for heating.

Substantial inaccuracies in model estimates may be less significant when considered at aggregate levels -as has been observed here. But for studies and analyses applying SAPbased models at smaller aggregate scales or at the individual dwelling level, such inaccuracies could be very significant. For example, an ability to accurately predict energy use at the individual dwelling level is crucial for schemes such as the Green Deal, where loans for energy efficiency measures are paid back through energy bills [29]. Inaccurate estimates of energy savings would lead to inaccurate predictions of associated cost savings and payback periods.

Beyond the analysis at the individual dwelling level, a series of model versus measurements comparisons were made at the level of average gas use, using average space heating user behaviours from the 405 EFUS dwellings. Comparisons against the average measured gas use for the 405 dwellings, the average measured gas use for 1,191 EFUS dwellings, and the sub national level average 2010 and 2011 DUKES gas consumption figures, showed model agreement within $2-3 \%$ in all cases. At the sub-national level this agreement is a substantial improvement over the previous model comparison based on assumed typical CHM behaviour. This suggests there is a strong case for revising the heating regimes in the CHM and (if SAP is to be used to estimate actual energy use, and not just relative energy use compared to other dwellings) in SAP. Based on this work we would advocate updating the regimes to a demand temperature of $20^{\circ} \mathrm{C}$, six months of heating, and 10 hours of heating a day for weekdays and weekends.

\section{Acknowledgements}

This study builds on Cambridge Architectural Research's work for the UK Government's Department of Energy and Climate Change from 2010 to 2015.

\section{References}

[1] H. M. Government. 2008. Climate Change Act 2008. The Stationery Office Ltd, Norwich, UK.

[2] Department of Energy \& Climate Change. 2013a. Energy Consumption in the UK (ECUK) Chapter 3: Domestic energy consumption in the UK between 1970 and 2012. London: DECC.

[3] Palmer, J. M. and Cooper, I. 2014. Great Britain's Housing Energy Fact File 2013. London: DECC.

[4] Department of Energy \& Climate Change. 2015. Energy Consumption in the UK (ECUK) Domestic data tables 2015 Update. London: DECC.

[5] Department of Energy \& Climate Change (DECC). 2010. SAP 2009: The Government's Standard Assessment Procedure for Energy Rating of Dwellings. 2009 edition, revised October 2010. Watford: Building Research Establishment. 
[6] Anderson, B. R., Chapman, P. F., Cutland, N. G., Dickson, C. M., Doran, S. M., Henderson, G., Henderson, J. H., Iles, P. J., Kosima, L., Shorrock, L. D. 2002. BREDEM-8 Model Description (2001 Update). Building Research Establishment (BRE), Garston, UK.

[7] Jones, P., Patterson, J., Lannon, S. 2007. Modelling the built environment at an urban scale - energy and health impacts in relation to housing. Landscape and Urban Planning, 83 (1), $39-49$.

[8] Atkinson, J. G. B., Jackson, T. and Mullings-Smith, E. 2009. Market influence on the low carbon energy refurbishment of existing multi-residential buildings. Energy Policy, 37 (7), 2582-2593.

[9] Cheng, V. and Steemers, K. 2011. Modelling domestic energy consumption at district scale: A tool to support national and local energy policies. Environmental Modelling \& Software, 26 (10), 1186-1198.

[10] Hughes M., Palmer J., Cheng V., Shipworth D. 2013. Sensitivity and uncertainty analysis of England's housing energy model, Building Research and Information, 41 (2), 156-167.

[11] Department of Energy \& Climate Change. 2012a. How the Green Deal will reflect the in-situ performance of energy efficiency measures. London: DECC.

[12] Department for Communities and Local Government (CLG). 2015. English Housing Survey HOMES 2013. July 2015, London. DCLG.

[13] Shipworth, M., Firth, S. K., Gentry, M., Wright, A. J., Shipworth, D., Lomas. K. J. 2010. Central Heating thermostat settings and timing: building demographics. Building Research \& Information, 38 (1), 50-69.

[14] Kane, T., Firth, S. K., Allinson, D., Irvine, K. N., Lomas, K. J. 2011. Understanding occupant heating practices in UK dwellings. World Renewables Energy Congress 2011; Energy End-Use Efficiency Issues, Linköping, Sweden, 8-11 May 2011.

[15] Kavgic, M., Mumovic, D., Summerfield, A., Stevanovic, Z., Ecium-Djuric, O. 2013. Uncertainty and modeling energy consumption: Sensitivity analysis for a city-scale domestic energy model. Energy and Buildings, 60, 1-11.

[16] Hughes M., Palmer J., Cheng V., Shipworth D. 2014. Global sensitivity analysis of England's housing energy model, Journal of Building Performance Simulation, Online 26 June 2014.

[17] Department of Energy and Climate Change (DECC). 2012b. Digest of UK Energy Statistics (DUKES) 2012: Long-term trends. London: DECC.

[18] H. M. Government. 2010. Approved Document Part L1A: Conservation of fuel and power in new dwellings (2010 Edition). London: Communities and Local Government.
[19] Department for Communities and Local Government (CLG). 2012. English Housing Survey HOMES 2010. July 2013, London. DCLG.

[20] Building Research Establishment (BRE). 2013a. Energy Follow Up Survey 2011: Report 11 - Methodology BRE report number 288851, Dec 2013. London: DECC.

[21] Building Research Establishment (BRE). 2013b. Energy Follow Up Survey 2011: Report 1 - Summary of findings, BRE report number 289605, Dec 2013. London: DECC.

[22] Building Research Establishment (BRE). 2013c. Energy Follow Up Survey 2011: Report 4 - Main heating systems, BRE report number 286733a, Dec 2013. London: DECC.

[23] Shorrock, L. D. and Dunster, J. E. 1997. The physically-based model BREHOMES and its use in deriving scenarios for the energy use and $\mathrm{CO}_{2}$ emissions of the UK housing stock, Energy Policy, 25 (10), 27-37.

[24] Johnston, D. Lowe, R., Bell M. 2005. An Exploration of the Technical Feasibility of Achieving $\mathrm{CO}_{2}$ Emission Reductions in Excess of 60\% Within the Housing Stock by the Year 2050, Energy Policy, 33 (13), 1643-1659.

[25] Shorrock, L. D., Dunster, J. E., Seale, C. F., Eppel, H., Lomas, K. J. 1994. Testing BREDEM-8 Against Measured Consumption Data and Against Simulation Models, Proceedings of Building Environmental Performance, BEPAC 1994.

[26] Taylor, S., Allinson, D., Firth, S., Lomas, K. 2013. Dynamic energy modelling of UK housing: evaluation of alternative approaches, Proceedings of BS 2013: 13th Conference of International Building Performance Simulation Association, Chambéry, France.

[27] Department of Energy \& Climate Change. 2014. National Energy Efficiency Data-Framework: Summary of analysis using the National Energy Efficiency Data-Framework (NEED). London: DECC.

[28] Hughes M., Palmer J., Pope P. 2013. A Guide to the Cambridge Housing Model. London: DECC.

[29] Huebner, G. M., McMichael, M., Shipworth, D., Shipworth, M., Durand-Daubin, M., Summerfield, A. 2013. Heating patterns in English homes: Comparing results from a national survey against common model assumptions. Building and Environment, 70, 298-305.

[30] Firth, S. K., Lomas, K. J., Wright, A. J. 2010. Targeting household energy-efficiency measures using sensitivity analysis. Building Research and Information, 38 (1), 25-41.

[31] Hopfe, C. J. and Hensen, J. L. M. 2011. Uncertainty analysis in building performance simulation for design support. Energy and Buildings, 43 (10), 2798-2805. 